\title{
The anesthetic management of button battery ingestion in children
}

\section{Prise en charge anesthésique suite à l'ingestion de pile bouton par l'enfant}

\author{
Richard J. Ing, MBBCh, FCA(SA) • Monica Hoagland, MD • Lena Mayes, MD • \\ Mark Twite, MBBChir, FRCP
}

Received: 7 June 2017/Revised: 25 September 2017/ Accepted: 2 October 2017/Published online: 22 November 2017

(c) Canadian Anesthesiologists' Society 2017

\begin{abstract}
Purpose Injuries related to button battery ingestion are common in children. This review provides an outline of the epidemiology, pathophysiology, management, and anesthetic implications in children who have ingested a button battery.

Source A literature search was conducted in the United States National Library of Medicine PubMed database using the terms "button battery ingestion" and "children' and "removal" and "surgery" and "anesthesia". Ninetysix articles published in English were found from 19832017, and 62 of these articles were incorporated into this review. Additionally, the Internet was searched with the terms "button battery ingestion and children" to identify further entities, organizations, and resources affiliated with button battery ingestion in children. These additional sources were studied and included in this review.

Principal findings Button batteries are ubiquitous in homes and electronic devices. Since 2006, largerdiameter and higher-voltage batteries have become available. These are more likely to become impacted in the esophagus after ingestion and lead to an increase in severe morbidity and mortality due to caustic tissue injury. Children at the highest risk for complications are those under six years of age who have ingested batteries $>20$ $\mathrm{mm}$ in diameter and sustain prolonged esophageal impaction at the level of the aortic arch with the negative pole oriented anteriorly.
\end{abstract}

R. J. Ing, MBBCh, FCA(SA) (ه) · M. Hoagland, MD .

L. Mayes, MD - M. Twite, MBBChir, FRCP

Department of Anesthesiology, Children's Hospital Colorado

and University of Colorado, Anschutz Medical Campus, 13123

E. 16th Ave, Aurora, CO, USA

e-mail: richard.ing@ childrenscolorado.org
Conclusion Anesthesiologists need to know about the epidemiology, pathophysiology, complications, and anesthetic management of children who have ingested button batteries.

\section{Résumé}

Objectif Les lésions liées à l'ingestion de piles boutons sont fréquentes chez les enfants. Ce compte-rendu résume l'épidémiologie, la physiopathologie, la prise en charge et les implications anesthésiques pour les enfants ayant avalé une pile bouton.

Source Une recherche de la littérature a été réalisée dans la base de données PubMed de la Bibliothèque nationale de médecine américaine à l'aide des termes "ingestion de pile bouton », " enfants », "retrait », "chirurgie» et " anesthésie » (soit 'button battery ingestion', 'children', 'removal', 'surgery' et 'anesthesia', respectivement). La recherche a dévoilé 96 articles publiés en anglais entre 1983 et 2017, dont 62 ont été intégrés à ce compte-rendu. Des recherches ont également été menées sur Internet avec les termes "ingestion de pile bouton et enfants» (soit 'button battery ingestion and children') afin d'identifier d'autres entités, organismes et ressources affiliés à l'ingestion de piles boutons par des enfants. Ces sources supplémentaires ont été étudiées et incluses dans ce compte-rendu.

Constatations principales Les piles boutons sont omniprésentes dans les lieux de vie et les appareils électroniques. Depuis 2006, des piles de diamètre plus grand et de voltage plus élevé sont disponibles. Le risque que ces dernières se logent dans l'oesophage après ingestion est plus élevé et cela entraîne une augmentation de la morbidité et mortalité en raison de lésions tissulaires caustiques. Les enfants qui courent le 
plus de risques de complications sont ceux de moins de six ans ayant avalé des piles d'un diamètre $>20 \mathrm{~mm}$ avec une impaction ossophagienne prolongée au niveau de l'arc aortique lorsque le pôle négatif est orienté antérieurement. Conclusion Les anesthésiologistes doivent connaître l'épidémiologie, la physiopathologie, les complications et la prise en charge des enfants ayant avalé des piles boutons.

Ingestion of foreign bodies is common in the pediatric population, with a peak incidence from six months to six years of age. ${ }^{1}$ In $2015,61 \%$ of all ingestions reported to the American Association of Poison Control Centers National Poison Data System (NPDS) occurred in patients under 20 yr of age. Additionally, 77\% of these ingestions occurred in children less than five years of age. ${ }^{2}$ Button battery ingestion occurs at a rate of 9.8 per million population annually, most often in children under six years of age $(67 \%) .^{3}$ Although most button battery ingestions resolve with either minor or no sequelae, there are multiple case reports of serious morbidity and mortality in the medical literature. The National Capital Poison Center compiled 55 fatalities from 1977-2016, and all occurred in children five years of age or less. ${ }^{4}$ Furthermore, 217 non-fatal button battery ingestions with severe esophageal or airway injury have been reported to the National Capital Poison Center since 1982. The incidence, presentation, and management of pediatric patients with button battery ingestion have been previously reviewed, however, this information has not been well published in the anesthesia literature. Anesthesiologists need to become familiar with managing children with button battery ingestion, as many will require anesthetic care for removal of the battery and management of subsequent complications. This review focuses on reports published in the medical literature in regards to the presentation, management, and outcomes of button battery ingestion in children. Finally, the anesthetic implications in these patients are considered.

\section{Epidemiology}

The incidence of button battery ingestions has remained stable over the last 30 years, ranging from 6.3-15.1 ingestions per million population annually. ${ }^{3}$ Nevertheless, the number of children presenting to emergency departments for battery-related injuries nearly doubled from 1990-2009. ${ }^{6}$ This may be due to increased exposure of children to household items containing button batteries, worsening injuries after exposure to larger batteries, or increased public awareness of the dangers of battery ingestion. The majority of children in these cases were less than five years old $(78.5 \%)$ and presented with battery ingestion (76.6\%), though exposure to the nasal cavity and ear canal were also common. ${ }^{6}$ More than 3,500 incidents of button battery ingestion are reported to the United States poison control centres annually, and this incidence is probably underreported. ${ }^{7}$ Ingested button batteries are most commonly obtained from an electronic product, though approximately one-third are found loose and a small number are obtained from the battery packaging. ${ }^{8}$ The batteries are most commonly intended for games, hearing aids, a variety of lights, electronic remote controls, and other household items. ${ }^{3,9}$

An early analysis in 1992 found that most button battery ingestions had either minor or no sequelae, with a $0.08 \%$ incidence of major morbidity and no fatalities. ${ }^{10}$ Subsequent analyses have shown a trend toward increasing morbidity and mortality despite a steady rate of battery ingestions. ${ }^{3,4}$ This is consistent with the large number of case reports in the medical literature of significant injury due to battery ingestions. The most recent data from the National Capital Poison Center indicate a $0.66 \%$ incidence of major morbidity or mortality, which represents a sevenfold increase over early estimates. ${ }^{9}$ The incidence of major morbidity increased dramatically in 2006, which correlates with the introduction of the 20-mm 3-volt lithium button battery to the household market $^{3}$ (Fig. 1). These larger more powerful batteries are more likely to become impacted in the esophagus on ingestion and cause more significant injury than earlier smaller less powerful batteries. In children under six years old, the rate of major morbidity or death after ingestion of a button battery $>20 \mathrm{~mm}$ in diameter is as high as $12.6 \% .^{3}$ The predictors of clinically significant morbidity or mortality after button battery ingestion include age less than four years, battery diameter $\geq 20 \mathrm{~mm}$, and multiple ingestions. ${ }^{3}$

\section{Clinical presentation}

Children who have ingested a button battery may be asymptomatic or present with non-specific symptoms that are often attributed to a respiratory or gastrointestinal illness. This can significantly delay presentation, diagnosis, and treatment, particularly when ingestion was unwitnessed in young children who are unable to give a pertinent history. The diagnosis of battery impaction in the esophagus was initially missed in $27 \%$ of major morbidity cases and $54 \%$ of fatal cases due to non-specific presenting symptoms. ${ }^{3}$ A review of button battery ingestions found that dysphagia, fever, and cough were the most common 


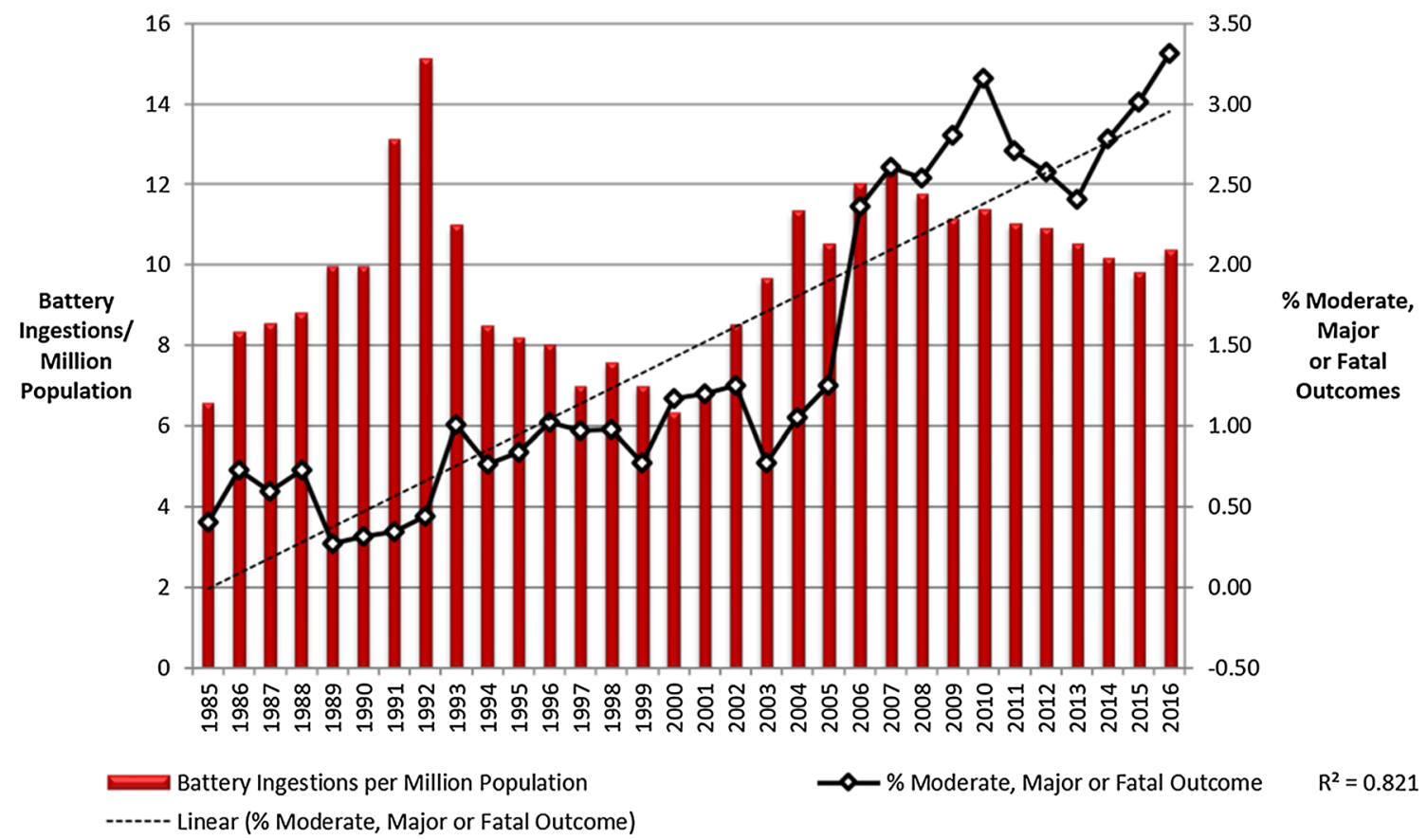

Fig. 1 National Capital Poison Center. Button Battery Ingestion Statistics. Available from URL: http://www.poison.org/battery/stats (accessed October 2017). Reproduced with permission ${ }^{9}$

presenting symptoms of a gastrointestinal button battery. ${ }^{11}$ Nevertheless, the presenting symptoms varied by age. Infants are more likely to present with irritability, anorexia, melena, and dysphonia. Toddlers more commonly present with fever, dyspnea, cough, drooling, and vomiting, and children older than five years are more likely to present with abdominal or thoracic pain. No conclusion could be drawn on the likelihood of any symptom being associated with a more severe injury. ${ }^{11}$

In children with a history of ingesting foreign objects, radiographs of the neck, chest, and abdomen should be obtained immediately. Impacted esophageal button batteries tend to occur at three levels. ${ }^{12}$ The commonest site is the thoracic inlet in the upper third of the esophagus associated with the cricopharyngeus muscle. This corresponds to the level of the clavicles on chest radiograph. The second site of narrowing is the midesophagus at the level of the left mainstem bronchus and aortic arch, ${ }^{12}$ and the third site is the lower esophageal sphincter at the gastroesophageal junction. ${ }^{13}$ Button batteries can be difficult to distinguish from coins due to their similar size and shape. Button batteries have a characteristic "double halo" appearance in an anterior view and a "step-off" appearance in a lateral view created by the junction of the positive and negative poles of the battery ${ }^{14}$ In contrast, coins do not have a double density on frontal images and have a much sharper edge with no visible step off on lateral images. ${ }^{14}$ Nevertheless, these signs may not be reliable if the radiograph is underpenetrated or not aligned correctly with the battery, and there are reports in the literature of ingested coins being mistaken for batteries and vice versa. ${ }^{15-17}$ Due to the potential dangers associated with button battery ingestions, if there is ever a question about the identity of the ingested foreign body, it should always be managed as if it were a button battery. ${ }^{17}$ Results of a recent radiological review of 276 button battery ingestions over a 15 -yr period at one institution indicated that, at the time of imaging, $62 \%$ of ingested batteries had reached the stomach and $10 \%$ had lodged in the esophagus at the level of the aortic arch. ${ }^{12}$

\section{Pathophysiology of button battery ingestion}

Risk stratification of patients is difficult following button battery ingestion and impaction because the resulting damage may be multifactorial. The extent of damage may be determined by the length of time since ingestion and the location of the battery if impaction has occurred. Additionally, the orientation, size, and voltage of the battery and any underlying esophageal and airway pathology of the patient play a role in the extent of the injury. The tissue injury observed after button battery exposure is due to the generation of an electric current that produces liquefaction and necrosis of the adjacent tissue. ${ }^{18}$ The contact of tissue with both poles of the battery effectively completes a circuit that allows current to flow and generates an alkaline environment at the negative pole 
of the battery. In animal studies, significant tissue damage can occur within $15 \mathrm{~min}$ of exposure to the battery, and damage is most severe in those areas in direct contact with the negative pole of the battery. ${ }^{19-21}$ Litovitz et al. have developed the helpful mnemonic of 3-Ns-i.e., "negative pole, narrowest, necrosis", to identify the area at highest risk for tissue damage. ${ }^{3}$ Pressure necrosis and leakage of the internal contents of the battery were not found to contribute significantly to tissue damage. ${ }^{22}$ Batteries $<20$ $\mathrm{mm}$ in diameter are less likely to become impacted in the esophagus but can cause injury in the nasal cavity or ear canal. ${ }^{18}$ Lithium batteries are more powerful than older alkaline batteries (3-volt vs 1.5 -volt batteries) and can therefore generate more current and hydroxide ions than other batteries, increasing the damage to surrounding tissue. Although new batteries are more likely to produce damage than used batteries, any button battery with a residual charge of $\geq 1.2$ volts can cause tissue damage. ${ }^{18}$ Therefore, even "spent" batteries that are unable to power electronic devices can still cause substantial injury. Due to the rapid development of tissue injury, the window for injury-free removal is generally considered to be less than two hours from ingestion. ${ }^{3}$ Nevertheless, tissue injury from ongoing alkali damage and breakdown of compromised tissues may continue for days to weeks following battery removal. $^{3,23}$

Numerous reports have documented the severity of damage following button battery ingestion in children. The National Capital Poison Center maintains a compilation of severe and fatal outcomes after button battery ingestion. ${ }^{4}$ The Table includes reported complications of esophageal button battery impaction. Delayed recognition of button battery ingestion, along with the possible need for transfer to hospitals with a higher level of care, can significantly prolong battery exposure to the tissue. This can make battery removal especially challenging, requiring the use of more invasive techniques, such as rigid esophagoscopy, which may increase the risk for iatrogenic injury.

Forty-four $(80 \%)$ of the 55 fatalities compiled by the National Capital Poison Center were due to hemorrhage. The most common cause of hemorrhage is aortoesophageal fistula (AEF), while other causes of fatalities include respiratory failure, sepsis, and cardiac arrest. ${ }^{4}$ The development of an AEF is an extremely ominous event, as there is only one reported case of survival after hemorrhage from a button battery-associated AEF. ${ }^{24}$ Other sites of vascular-esophageal fistulae include the subclavian, carotid, thyroid and pulmonary arteries, anomalous subclavian arteries, and vascular rings. ${ }^{25}$ Approximately $60 \%$ of patients with a fatal hemorrhage die prior to or during the removal of an impacted battery. The remainder of patients survive the initial battery removal but present with delayed hemorrhage as late as four weeks (28 days) after removal. ${ }^{4}$ Approximately $70 \%$ of cases present with a sentinel bleeding event in an otherwise stable patient. ${ }^{23}$ A sentinel bleed should therefore be used as an indication for immediate escalation of care to a high-acuity setting. Other causes of fatalities include respiratory failure, sepsis, and cardiac arrest. ${ }^{4}$ Despite these severe complications, many patients appear well enough after button battery removal to be discharged home prior to their hemorrhage. This should prompt clinicians to evaluate ongoing tissue injury by following up with more extensive imaging, such as a computerized tomography angiogram (CTA) or magnetic resonance imaging (MRI), to exclude an impending vascular fistula and evaluate wound healing prior to discharge. The managing physician makes the decision to pursue further imaging based on risk factors such as the extent and location of the original injury and risk factors discussed later in this review. This is very relevant for anesthesiologists, as they are often called upon to provide anesthesia for these young patients during CT and MRI scans.

\section{Management of button battery ingestions}

Guidelines for the management of button battery ingestions have recently been published by the Button Battery Task Force affiliated with the American Academy of Pediatrics, the American Society for Gastrointestinal Endoscopy, and the North American Society for Pediatric Gastroenterology, Hepatology and Nutrition (NASPGHAN). ${ }^{1,7,18,26}$ In addition, management guidelines were updated by the National Capital Poison Center in September 2016. ${ }^{27}$ All of these guidelines emphasize the need for rapid triage and management of patients presenting with button battery ingestion. The goal for battery removal is within two hours of ingestion, but this may not be feasible if there is any delay in either patient presentation to a medical facility or recognition of battery ingestion. At many institutions, the goal is to have the patient in the operating room within $60 \mathrm{~min}$ of presentation to the facility. ${ }^{28} \mathrm{~A}$ recent trial showed that activating a trauma protocol for patients suspected of button battery ingestion decreased the time from hospital presentation to the operating room by $110 \mathrm{~min} .{ }^{29}$ Patients suspected of having ingested a button battery should have immediate anteroposterior and lateral $x$-rays of the neck, chest, and abdomen. These investigations can be deferred if the child is more than 12 yr old and developmentally normal; the button battery is known to be $<12 \mathrm{~mm}$ in diameter; there is no co-ingestion of other foreign bodies; and the patient has no preexisting esophageal disease and has been completely asymptomatic since the ingestion. ${ }^{18,26}$ 
In 2015, the NASPGHAN published the most recent management guidelines, which are summarized below and included in Fig. $2 .{ }^{26}$ If a button battery is noted to be in the esophagus on $x$-ray, it must be immediately removed regardless of the patient's age, symptoms or size of the battery, or time of the last meal. In addition, button batteries located in the stomach with the presence of any symptoms should be urgently removed. ${ }^{18,26}$ Removal of the

Table Major complications reported from button battery ingestion

\begin{tabular}{|c|c|c|}
\hline Type of injury & Specific complication & Reference(s) \\
\hline \multirow[t]{3}{*}{ Esophageal injury } & Esophageal ulceration & 28,46 \\
\hline & Esophageal perforation & 37,47 \\
\hline & Esophageal stricture & 21,47 \\
\hline \multirow[t]{2}{*}{ Esophageal fistulae } & $\begin{array}{l}\text { Vascular-esophageal fistulae (aorta, aberrant right subclavian artery, } \\
\text { thyroid artery, left common carotid artery, posterior aortic arch, vascular ring) }\end{array}$ & $4,23,25,30,48-54$ \\
\hline & Tracheoesophageal fistulae & $35,41,52,55-58$ \\
\hline \multirow[t]{2}{*}{ Mediastinal injury } & Pneumothorax & $44,45,59$ \\
\hline & Pneumomediastinum & 44,45 \\
\hline \multirow[t]{2}{*}{ Airway complications } & Vocal cord injury & 60,61 \\
\hline & Croup & 13,62 \\
\hline \multirow[t]{2}{*}{ Infectious complications } & Mediastinitis & 44 \\
\hline & Spondylodiscitis & $63-66$ \\
\hline
\end{tabular}

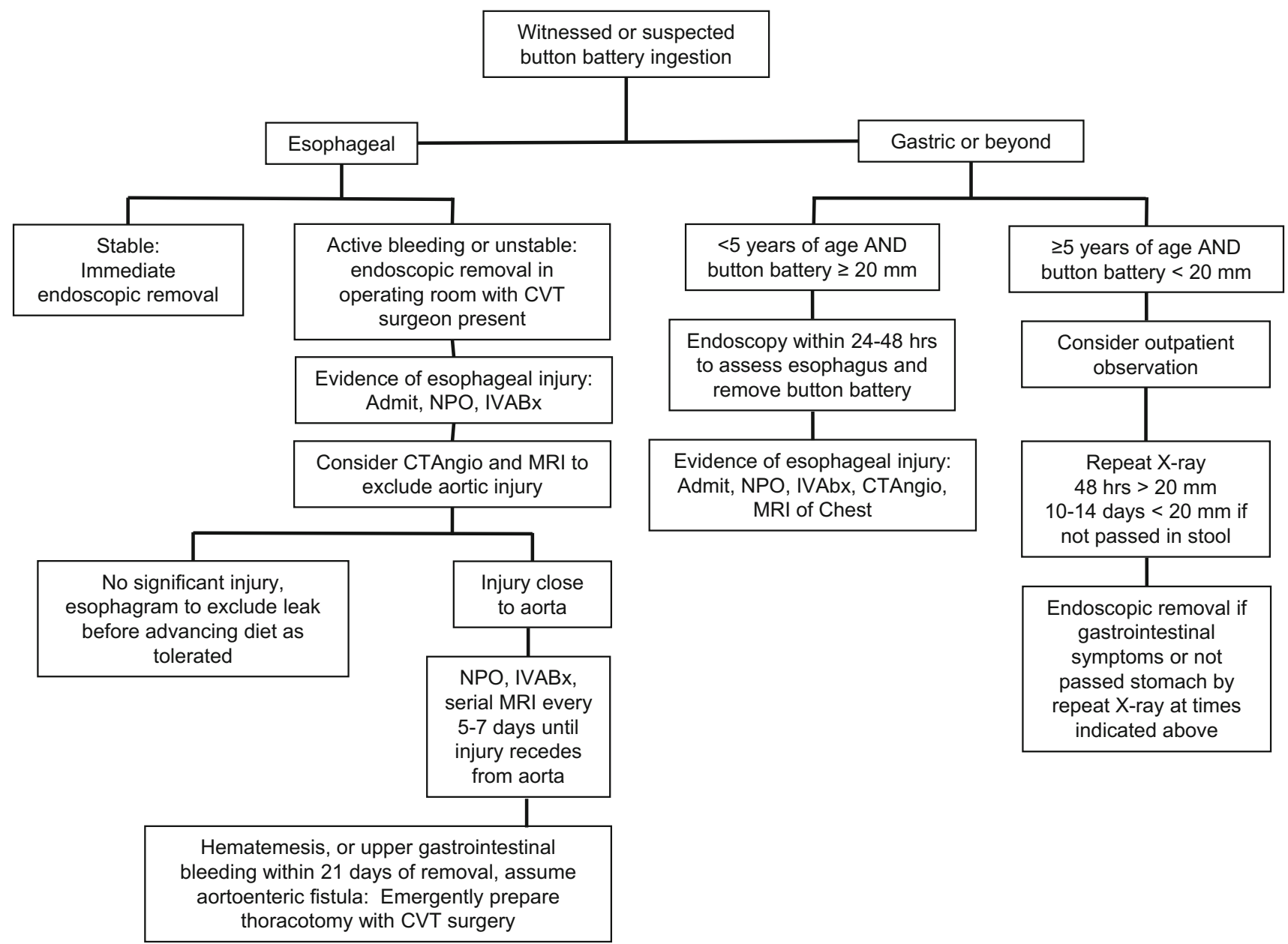

Fig. 2 Algorithm for the management of button battery ingestion. CVT = cardiovascular thoracic, NPO = nil per os, IVABx = intravenous antibiotics, CTAngio $=$ computed tomographic angiogram, MRI $=$ magnetic resonance imaging. Reproduced with permission ${ }^{26}$ 
battery should be performed endoscopically, and the esophageal mucosa should be directly visualized to assess tissue damage. There is disagreement among guidelines regarding the management of asymptomatic button batteries in the stomach, the majority of which will pass uneventfully through the gastrointestinal tract without any intervention. ${ }^{1}$ Initial guidelines recommend that asymptomatic patients should be observed and followed with serial $x$-rays to document the passage of the battery. Removal is advised only if the battery does not pass through the stomach after several days. ${ }^{1,18}$ More recent guidelines emphasize that a battery in the stomach may have previously been impacted in the esophagus with the potential for unrecognized esophageal damage. Considering the growing medical literature concerning potentially fatal complications of battery impactions in the esophagus, the NASPGHAN recently updated their recommendations for the management of asymptomatic gastric batteries. Patients less than five years old or with a button battery $\geq 20 \mathrm{~mm}$ in diameter in the stomach should undergo endoscopy to remove the battery, and the esophagus should be assessed for mucosal damage. In accordance with previous guidelines, patients five years and older with a button battery $<20 \mathrm{~mm}$ in diameter may be observed with serial imaging and undergo endoscopic removal if the battery does not pass. ${ }^{26}$

There is limited high-quality evidence to guide definitive clinical recommendations at all hospitals due to differences in hospital resources. ${ }^{30}$ Nevertheless, common to all button battery removals in children is the need for an anesthesiologist with experience in managing pediatric patients. The anatomical site of the impacted battery and the perceived risk of bleeding determine the optimal location and combination of medical staff for button battery removal. Very little evidence exists to guide true evidence-based risk stratification in these patients. Certain patients with esophageal button battery impaction are thought to be at high risk for hemorrhage. These include patients five years of age or less with prolonged impaction of a battery $\geq 20 \mathrm{~mm}$ in diameter below the thoracic inlet at the level of the aorta or patients who have had a sentinel bleed. ${ }^{28}$ Brumbaugh et al. have shown that as many as $70 \%$ of fatal cases of hemorrhage present with a history of mild bleeding preceding their exsanguination. ${ }^{30}$ These patients may best be managed in the cardiac operating room or cardiac catheterization laboratory with cardiothoracic surgeons, interventional cardiologists, and gastroenterologists available. ${ }^{23,26,28,30}$ The advantages of these locations include the ability to obtain large-bore venous and arterial access without delay, perform aortic angiography to assess for potential vascular injury, ${ }^{30,31}$ utilize endovascular interventions to control bleeding from an aortoenteric fistula, ${ }^{32-34}$ initiate extracorporeal membrane oxygenation or cardiopulmonary bypass, and perform open vascular repair. ${ }^{35}$ Patients with an esophageal button battery who have not had a sentinel bleed may be managed in the main operating room by gastroenterologists or otolaryngologists with pediatric surgeons on standby. ${ }^{30}$ The important aspect of care is the presence of colleagues trained in pediatric airway management and endoscopy. Patients at lowest risk may be managed in a well-staffed procedure suite. Such patients include older children with a small or asymptomatic gastric or intestinal button battery who are appropriately fasted and are undergoing non-emergent endoscopy after failure of expectant management. ${ }^{26,28,30}$ Given the urgent nature of battery removal, it is imperative that all necessary teams are quickly mobilized. For patients presenting in remote areas, however, the benefit of transferring patients to a higher-level facility must be weighed against the expense of a potentially significant delay in removing the battery. In that situation, the medical and surgical teams may determine that removing the battery in the remote location is in the best interest of the patient despite the lack of resources available at a tertiary care hospital.

Following battery removal, patients with esophageal injury must be admitted to an inpatient service, often to an intensive care unit. Patients should be closely monitored for respiratory or hemodynamic symptoms that can indicate the development of tracheal or vascular fistulae, particularly in cases where the negative pole of the battery was directed anteriorly towards vascular and airway structures. The risk for spondylodiscitis is elevated when the negative pole of the battery is directed posteriorly. ${ }^{28,36}$ Impaction in the proximal esophagus can be associated with thyroid artery injury, tracheoesophageal fistula, or vocal cord injury, while those in the mid or lower esophagus are at highest risk for causing an aortoesophageal fistula. ${ }^{24}$ Circumferential damage increases the risk for future stricture formation. ${ }^{28}$ Given the potential for ongoing esophageal damage with delayed complications, the patient should undergo serial evaluations, including esophagrams to assess for stricture and perforation, endoscopy to evaluate for stricture and mucosal damage, and noninvasive imaging (CTA or MRI) to assess for extra-esophageal injury. ${ }^{18,26,30}$ In some institutions, there is a preference for noninvasive imaging over endoscopy. Endoscopic evaluation may underestimate the degree of submucosal injury present, while noninvasive imaging allows a more comprehensive assessment of both esophageal and extra-esophageal injury without causing further damage to friable tissues. ${ }^{26}$ Nevertheless, the choice of surveillance modality is institution dependent. Although most pediatric patients will still require an anesthetic, radiographic imaging eliminates the potential for further esophageal damage related to repeated endoscopy while 
also allowing practitioners to follow the evolution of extraesophageal injury and involvement of vascular structures. $^{28,30}$ Decisions regarding the duration of inpatient stay, choice of serial imaging, return to normal diet, and outpatient follow-up are made at the discretion of the treating physician and are based on such factors as anatomical location and duration of initial impaction, presenting symptoms, esophageal injury noted at battery removal and on follow-up examinations, and patient proximity to medical care. ${ }^{28,30}$

Postoperative medical and surgical management can include prolonged esophageal rest with gastrostomy or parenteral nutrition, prolonged courses of antibiotics or steroids, and hemodynamic and respiratory support, depending on the initial injury. Subsequent surgical interventions include esophageal reconstruction, closure of tracheoesophageal fistulae, tracheostomy, and serial esophageal dilations. ${ }^{28,30,37-39}$ Esophageal and tracheal reconstruction may be delayed due to concerns for infection and may require complex techniques such as rotational muscle flaps. ${ }^{40}$ Alternatively, patients may require an esophagectomy with cervical esophagostomy. ${ }^{41}$

\section{Anesthetic considerations}

Every child who ingests a button battery has a unique set of risk factors that must be assessed when determining the appropriate plan of care. As previously mentioned, the patients at highest risk are those less than five years of age with an impacted battery $>20 \mathrm{~mm}$ in diameter in the esophagus at the level of the aortic arch, particularly if the negative pole is oriented anteriorly or there has been a sentinel bleed. Intermediate-risk patients are those with an esophageal battery impaction or symptomatic gastric button battery who have not had a sentinel bleed. Lowrisk patients are those who are more than five years of age with asymptomatic gastric battery $<20 \mathrm{~mm}$ in diameter and no history of esophageal pathology. The successful care of these complicated patients requires a multidisciplinary coordinated team approach. The team may include emergency physicians, anesthesiologists, pediatric gastroenterologists, pediatric surgical specialists (including general, ENT [ear, nose, and throat], and cardiothoracic surgeons), radiologists, interventional cardiologists, and cardiac perfusionists, as clinically indicated. The anesthesiologist must understand the potential anatomic and physiologic implications of the patient's injury and help coordinate care among the various specialists involved in treating the patient. This may help expedite battery removal while also minimizing the risk for iatrogenic injury and vascular, hemodynamic, or respiratory complications.
Minimizing the time from battery ingestion to removal is essential to decrease the degree of tissue injury. ${ }^{29}$ Due to the emergent nature of the procedure, nil per os guidelines $^{42}$ prior to anesthesia are irrelevant and therefore not followed. As with any esophageal foreign body, the patient should be considered at risk for aspiration of esophageal or gastric contents. Recent experimental evidence has shown that topical administration of a dilute acid neutralizes the alkaline environment created by the button battery and decreases the esophageal injury seen after ingestion. ${ }^{43}$ The problem is that it is not easy to establish if an esophageal perforation is present prior to performing endoscopy or radiological imaging. It is theoretically a good idea to drink $5 \mathrm{~mL}$ of an acidic drink (such as soda or orange juice) every five minutes from the time of battery ingestion until removal, but it is not being recommended in clinical practice because there is concern regarding ingesting liquid if an unrecognized perforation of the esophagus exists. ${ }^{27,43}$ Nitrous oxide should be avoided during anesthesia. In conjunction with excessive insufflation of air during endoscopy, it could worsen any pneumothorax or pneumomediastinum associated with an esophageal perforation. ${ }^{44,45}$ Intravenous access should be obtained prior to anesthetic induction, and the patient's airway should be secured with a rapid sequence induction, further minimizing the risks of tracheal aspiration of gastric or esophageal contents. Consideration may be given to inhalational induction in patients when the location of the battery is unknown and an airway foreign body is suspected. Such patients would include those with impaction at the level of the aortic arch with an anteriorly oriented negative pole or a previous sentinel bleed. These patients may be dehydrated and may need rapid fluid resuscitation in the perioperative setting. Furthermore, because of potential airway edema, a smaller endotracheal tube may be needed. A nasogastric tube should not be placed because of the risk of causing an esophageal perforation due to friable tissue with potentially catastrophic consequences.

Following induction of anesthesia, the patient's eyes should always be protected. Once the airway is secured, preparations are made for endoscopic removal of the button battery as well as for an open surgical procedure in case endoscopic removal is unsuccessful or a penetrating injury of the esophagus is found. At least two large-bore intravenous lines that allow for rapid volume resuscitation are recommended. Preparations are also required for possible blood transfusion, including having cross-matched blood and a blood warmer available in the operating room. Intra-arterial access is recommended and central venous cannulation may be necessary in patients at high risk for vascular involvement, including those with an impacted battery at the level of the aortic arch with an 
anteriorly oriented negative pole or those with a previous sentinel bleed. It may be advisable to cannulate the femoral vein in case surgical intervention in the neck or chest becomes necessary. ${ }^{31}$ During endoscopy and battery removal, the anesthesiologist must be vigilant and guard against accidental tracheal extubation or airway compression from the endoscope; consequently, manual hand ventilation may be preferable to mechanical ventilation during endoscopy, as both of these complications will be detected early. If endoscopic removal of the button battery is successful, the esophagus will be re-examined to assess mucosal integrity and to find any evidence of penetrating injury. If no penetrating injury exists, the area may be irrigated with a $150-\mathrm{mL}$ dilute acidic solution to decrease ongoing esophageal damage. ${ }^{27,43}$ Following irrigation of the esophagus, the stomach should be aspirated of all contents to minimize risks of aspiration during subsequent bronchoscopy.

After button battery removal, a bronchoscopy is usually performed to assess for tracheal injury. Usually flexible bronchoscopy is sufficient; however, for a battery impacted in the proximal esophagus, extubation may be required to assess the tracheal mucosa adequately. In this situation, bronchoscopy may be feasible through a laryngeal mask airway device or, in rare cases, rigid bronchoscopy may be required. Therefore, the patient should be breathing spontaneously and maintained on intravenous or volatile anesthesia with topical lidocaine administered to the larynx and lower airway to blunt the coughing reflex. Following the examination, a narrow-diameter feeding tube may be placed under direct visualization by esophagoscopy to provide nutrition and allow for esophageal rest and recovery in children expected to require long-term feeding. The patient will require inpatient admission, with consideration for an intensive care setting in highrisk patients (as described above) or those with extensive esophageal injury noted during battery removal. The decision to remove the endotracheal tube and perform tracheal extubation at the end of the procedure is based on the respiratory and hemodynamic status of the patient, the degree of esophageal and airway injury noted intraoperatively, and the plan for subsequent diagnostic procedures. This decision should therefore be made by the anesthesiologist in conjunction with the intensivist, gastroenterologist, or surgeon who will be caring for the patient.

\section{Conclusion}

Foreign body ingestions are common in the pediatric population. Button battery ingestions are particularly dangerous and carry a significant potential for mortality and long-term morbidity. Importantly, children suspected of ingesting a button battery must be triaged and treated quickly and appropriately. Proposed algorithms for management of button battery ingestions have been published in the gastrointestinal, surgical, and emergency medicine literature. ${ }^{26,27}$ While anesthesiologists are almost always involved with the interventional management of these patients, there is scant information published on this topic in the anesthesia literature. It is essential for anesthesiologists who understand the serious risks of button battery ingestions, both at the time of ingestion and during follow-up procedures, to have early involvement in providing safe care for these patients.

Conflicts of interest None declared.

Editorial responsibility This submission was handled by Dr. Gregory L. Bryson, Deputy Editor-in-Chief, Canadian Journal of Anesthesia.

Author contributions Richard Ing, Monica Hoagland, Lena Mayes, and Mark Twite contributed substantially to all aspects of this manuscript, including conception and design; acquisition, analysis, and interpretation of data; and drafting the article.

\section{References}

1. ASGE Standard of Practice Committee, Ikenberry SO, Jue TL, Anderson MA, et al. Management of ingested foreign bodies and food impactions. Gastrointest Endosc 2011; 73: 1085-91.

2. Mowry JB, Spyker DA, Brooks DE, McMillan N, Schauben JL. 2014 Annual Report of the American Association of Poison Control Centers' National Poison Data System (NPDS): 32nd annual report. Clin Toxicol (Phila) 2015; 53: 962-1147.

3. Litovitz T, Whitaker N, Clark L, White NC, Marsolek M. Emerging battery-ingestion hazard: clinical implications. Pediatrics 2010; 125: 1168-77.

4. National Capital Poison Center. Fatal Button Battery Ingestions: 56 reported cases. Available from URL: http://www.poison.org/ battery/fatalcases (accessed October 2017).

5. National Capital Poison Center. Nonfatal Button Battery Ingestions with Severe Esophageal or Airway Injury: 225 cases. Available from: http://www.poison.org/battery/severecases (accessed October 2017).

6. Sharpe SJ, Rochette LM, Smith GA. Pediatric battery-related emergency department visits in the United States, 1990-2009. Pediatrics 2012; 129: 1111-7.

7. American Academy of Pediatrics. Button Battery Task Force. The Hazards of Button Batteries - 2015. Available from URL: https:// www.aap.org/en-us/advocacy-and-policy/aap-health-initiatives/ pages/Button-Battery.aspx (accessed October 2017).

8. Litovitz T, Whitaker N, Clark L. Preventing battery ingestions: an analysis of 8648 cases. Pediatrics 2010; 125: 1178-83.

9. National Capital Poison Center. Button Battery Ingestion Statistics. Available from URL: http://www.poison.org/battery/ stats (accessed October 2017).

10. Litovitz T, Schmitz BF. Ingestion of cylindrical and button batteries: an analysis of 2382 cases. Pediatrics 1992; 89: 747-57. 
11. Buttazzoni E, Gregori D, Paoli B, et al. Symptoms associated with button batteries injuries in children: an epidemiological review. Int J Pediatr Otorhinolaryngol 2015; 79: 2200-7.

12. Pugmire BS, Lin TK, Pentiuk S, de Alarcon A, Hart CR, Trout AT. Imaging button battery ingestions and insertions in children: a 15year single-center review. Pediatr Radiol 2017; 47: 178-85.

13. Cruz CI, Patel D. Impacted button-battery masquerading as croup. J Emerg Med 2013; 45: 30-3.

14. Maves MD, Lloyd TV, Carithers JS. Radiographic identification of ingested disc batteries. Pediatr Radiol 1986; 16: 154-6.

15. Frumkin $K$, Lanker $M$. Suspected esophageal coin-look again. Am J Emerg Med 2016; 34: 680.e3-4.

16. Bernstein JM, Burrows SA, Saunders MW. Lodged oesophageal button battery masquerading as a coin: an unusual cause of bilateral vocal cord paralysis. Emerg Med J 2007; 24: e15.

17. Gan RW, Nasher O, Jackson PB, Singh SJ. Diagnosis of button battery ingestion by 'halo' radiographic sign: an exception to the rule. BMJ Case Rep 2015. https://doi.org/10.1136/bcr-2015209908.

18. Jatana KR, Litovitz T, Reilly JS, Koltai PJ, Riders G, Jacobs IN. Pediatric button battery injuries: 2013 task force update. Int J Pediatr Otorhinolaryngol 2013; 77: 1392-9.

19. Tanaka J, Yamashita M, Yamashita M, Kajigaya H. Esophageal electrochemical burns due to button type lithium batteries in dogs. Vet Hum Toxicol 1998; 40: 193-6.

20. Yoshikawa T, Asai S, Takekawa Y, Kida A, Ishikawa $K$. Experimental investigation of battery-induced esophageal burn injury in rabbits. Crit Care Med 1997; 25: 2039-44.

21. Maves MD, Carithers JS, Birck HG. Esophageal burns secondary to disc battery ingestion. Ann Otol Rhinol Laryngol 1984; 93: 364-9.

22. Yamashlta $M$, Saito $S$, Koyama $K$, Hattori H, Ogata $T$. Esophageal electrochemical burn by button-type alkaline batteries in dogs. Vet Hum Toxicol 1987; 29: 226-30.

23. Brumbaugh D, Kramer RE, Litovitz T. Hemorrhagic complications following esophageal button battery ingestion. Arch Otolaryngol Head Neck Surg 2011; 137: 416; author reply 416-7.

24. Spiers A, Jamil S, Whan E, Forbes D, Gollow I, Andrews D. Survival of patient after aorto-oesophageal fistula following button battery ingestion. ANZ J Surg 2012; 82: 186-7.

25. Mercer RW, Schwartz MC, Stephany J, Donnelly LF, Franciosi $J P$, Epelman M. Vascular ring complicates accidental button battery ingestion. Clin Imaging 2015; 39: 510-2.

26. Kramer RE, Lerner DG, Lin T, et al. Management of ingested foreign bodies in children: a clinical report of the NASPGHAN Endoscopy Committee. J Pediatr Gastroenterol Nutr 2015; 60: 562-74.

27. National Capital Poison Center. NBIH Button Battery Ingestion Triage and Treatment Guideline. Available from URL: http:// www.poison.org/battery/guideline (accessed October 2017).

28. Leinwand $K$, Brumbaugh DE, Kramer RE. Button battery ingestion in children: a paradigm for management of severe pediatric foreign body ingestions. Gastrointest Endosc Clin N Am 2016; 26: 99-118.

29. Russell RT, Griffin RL, Weinstein E, Billmire DF. Esophageal button battery ingestions: decreasing time to operative intervention by level I trauma activation. J Pediatr Surg 2014; 49: 1360-2.

30. Brumbaugh DE, Colson SB, Sandoval JA, et al. Management of button battery-induced hemorrhage in children. J Pediatr Gastroenterol Nutr 2011; 52: 585-9.

31. Ing RJ, Kramer RE, Darst J, Mayes LM, Twite MD. Button battery ingestion in children: a role for angiography? Can J Anesth 2017; 64: 321-2.
32. Taylor BJ, Stewart D, West P, Dunn JT, Cisek P. Endovascular repair of a secondary aortoesophageal fistula: a case report and review of the literature. Ann Vasc Surg 2007; 21: 167-71.

33. Krieves MA, Merritt GR, Nichols CS, et al. Aortoesophageal fistula and coarctation of the aorta in a 15-year-old child. Semin Cardiothorac Vasc Anesth 2013; 17: 294-7.

34. Jonker FH, Heijmen $R$, Trimarchi S, Verhagen HJ, Moll FL, Muhs BE. Acute management of aortobronchial and aortoesophageal fistulas using thoracic endovascular aortic repair. J Vasc Surg 2009; 50: 999-1004.

35. Slamon NB, Hertzog JH, Penfil SH, Raphaely RC, Pizarro C, Derby $C D$. An unusual case of button battery-induced traumatic tracheoesophageal fistula. Pediatr Emerg Care 2008; 24: 313-6.

36. Young A, Tekes A, Huisman TA, Bosemani T. Spondylodiscitis associated with button battery ingestion: prompt evaluation with MRI. Neuroradiol J 2015; 28: 504-7.

37. Soccorso G, Grossman O, Martinelli M, et al. $20 \mathrm{~mm}$ lithium button battery causing an oesophageal perforation in a toddler: lessons in diagnosis and treatment. Arch Dis Child 2012; 97: 7467.

38. Russell RT, Cohen M, Billmire DF. Tracheoesophageal fistula following button battery ingestion: successful non-operative management. J Pediatr Surg 2013; 48: 441-4.

39. Ruhl DS, Cable BB, Rieth KK. Emergent treatment of button batteries in the esophagus: evolution of management and need for close second-look esophagoscopy. Ann Otol Rhinol Laryngol 2014; 123: 206-13.

40. Milford K, Numanoglu A, Brooks A. Cox Sl. Button batteries in the oesophagus: a surgical emergency. S Afr Med J 2016; 106: 978-80.

41. Wurzel DF, Masters IB, Choo KL, Isles AF. A case for early bronchoscopic airway assessment after disc battery ingestion. Pediatr Pulmonol 2014; 49: E72-4.

42. Merchant $R$, Chartrand D, Dain $S$, et al. Guidelines to the Practice of Anesthesia - revised edition 2016. Can J Anesth 2016; 63: 86-112.

43. Jatana KR, Rhoades K, Milkovich S, Jacobs IN. Basic mechanism of button battery ingestion injuries and novel mitigation strategies after diagnosis and removal. Laryngoscope 2017; 127: 1276-82.

44. Parray T, Siddiqui SM, Hughes $M$, Shah $S$. Tension pneumothorax and subcutaneous emphysema during retrieval of an ingested lithium button battery. J Anesth 2010; 24: 469-71.

45. Westbrook JL, Stevens JE. Button battery ingestion and its sequelae, implications for the anaesthetist: a case report and review. Pediatr Anesth 1992; 2: 253-9.

46. Banerjee R, Rao GV, Sriram PV, Reddy KS, Reddy DN. Button battery ingestion. Indian J Pediatr 2005; 72: 173-4.

47. Gordon AC, Gough MH. Oesophageal perforation after button battery ingestion. Ann R Coll Surg Engl 1993; 75: 362-4.

48. Guinet T, Gaulier JM, Moesch C, Bagur J, Malicier D, Maujean $G$. Sudden death following accidental ingestion of a button battery by a 17-month-old child: a case study. Int J Legal Med 2016; 130: 1291-7.

49. Mortensen A, Hansen NF, Schiodt OM. Cardiac arrest in child caused by button battery in the oesophagus and complicated by aorto-oesophageal fistula (Danish). Ugeskr Laeger 2009; 171: 3098-9.

50. Sigalet DL, Laberge JM, DiLorenzo M, et al. Aortoesophageal fistula: congenital and acquired causes. J Pediatr Surg 1994; 29: $1212-4$.

51. Shabino CL, Feinberg AN. Esophageal perforation secondary to alkaline battery ingestion. JACEP 1979; 8: 360-3.

52. Hamilton JM, Schraff SA, Notrica DM. Severe injuries from coin cell battery ingestions: 2 case reports. J Pediatr Surg 2009; 44: 644-7. 
53. Soerdjbalie-Maikoe $V$, van Rijn RR. A case of fatal coin battery ingestion in a 2-year-old child. Forensic Sci Int 2010; 198: e1922.

54. Blatnik DS, Toohill RJ, Lehman RH. Fatal complication from an alkaline battery foreign body in the esophagus. Ann Otol Rhinol Laryngol 1977; 86: 611-5.

55. Provenzano MJ, Rutter MJ, von Allmen $D$, et al. Slide tracheoplasty for the treatment of tracheoesophogeal fistulas. J Pediatr Surg 2014; 49: 910-4.

56. Gopal M, Westgarth-Taylor C, Loveland J. Repair of tracheooesophageal fistula secondary to button battery ingestion: a combined cervical and median sternotomy approach. Afr J Paediatr Surg 2015; 12: 91-3.

57. Anand TS, Kumar S, Wadhwa V, Dhawan R. Rare case of spontaneous closure of tracheo-esophageal fistula secondary to disc battery ingestion. Int $\mathrm{J}$ Pediatr Otorhinolaryngol 2002; 63: $57-9$.

58. Tibballs $J$, Wall $R$, Koottayi SV, et al. Tracheo-oesophageal fistula caused by electrolysis of a button battery impacted in the oesophagus. J Paediatr Child Health 2002; 38: 201-3.

59. Samad L, Ali M, Ramzi H. Button battery ingestion: hazards of esophageal impaction. J Pediatr Surg 1999; 34: 1527-31.
60. Simonin M, D’Agostino I, Lebreton M, Jughon O, Hamza J, Oualha $M$. Bilateral vocal palsy following coin cell lithium battery ingestion: a case report and review. Eur J Pediatr 2013; 172: 991-3.

61. Nagao N, Kaneko T, Hikawa Y, Yanagihara S. Laryngeal edema and vocal cord paralysis due to lithium battery ingestion; a case report (Japanese). Masui 2007; 56: 956-8.

62. Gohil $R$, Culshaw J, Jackson P, Singh S. Accidental button battery ingestion presenting as croup. J Laryngol Otol 2014; 128: 292-5.

63. Eshaghi H, Norouzi $S$, Heidari-Bateni $G$, Mamishi $S$. Spondylodiscitis: a rare complication of button battery ingestion in a 10-month-old boy. Pediatr Emerg Care 2013; 29: 368-70.

64. Sudhakar PJ, Al Dossary J, Malik N. Spondylodiscitis complicated by the ingestion of a button battery: a case report. Korean J Radiol 2008; 9: 555-8.

65. Jarugula $R$, Dorofaeff $T$. Oesophageal button battery injuries: think again. Emerg Med Australas 2011; 23: 220-3.

66. Tan A, Wolfram $S$, Birmingham $M$, Dayes $N$, Garrow $E$. Zehtabchi S4. Neck pain and stiffness in a toddler with history of button battery ingestion. J Emerg Med 2011; 41: 157-60. 